Farm animal welfare - who writes the rules?

Occasional Publication No. 23 - British Society of Animal Science 1999

edited by A. J. F. Russel, C. A. Morgan, C. J. Savory, M. C. Appleby and T. L. J. Lawrence

\title{
Revealing public preferences for farm animal welfare
}

\author{
D. E. B. Burgess, W. G. Hutchinson and J. Davis \\ Department of Agricultural Economics, The Queen's University of Belfast, Newforge Lane, Belfast BT9 5PX
}

Farm animal welfare is an issue of great public concern, illustrated by the sheer volume of letters sent to both MPs and MEPs and the amount of press coverage given to the issue. This is not in doubt. However, the question which has yet to be answered is how much does the public actually VALUE farm animal welfare? How much will the public be prepared to pay to increase the welfare of animals?

If the public are prepared to pay for improving animal welfare, then this finding would justify research into animal welfare. Alternatively, if the public are unwilling to pay for improvements, does this mean that research into animal welfare is seen as irrelevant to the public? The value of animal welfare is based on the preferences of the public and such preferences may indicate areas of greater and lesser welfare concern and of willingness to pay. However, how valid are these preferences for animal welfare? Are the public able to order their preferences rationally over this very emotive subject? If the public are unable to order preferences rationally, this casts doubt on their ability to value animal welfare and to contribute towards decisions made on animal welfare matters.

In order to determine how much the public value animal welfare, a survey will be undertaken to reveal both the public's willingness to pay and their preferences between several potential welfare improvements. If the preferences are ordered rationally, then consistency will be present internally and externally. Preferences are consistent internally when given three choices $(A, B$ or $C)$. A is preferred to $B, B$ is preferred to $C$ and $A$ is preferred to $C$. External consistency occurs when different elicitation methods reveal the same preference order.

The study is based on four welfare improvement schemes. In the first programme, the welfare of the dairy cow is improved by changing the winter housing of cattle from cubicles to straw yards in order to reduce lameness. The second scheme involves changing from fast-growing breeds of broiler chickens to slower growing breeds to improve leg quality. The third and fourth programmes enlarge and enrich the cages and pens of laying hens and pigs respectively, in order to enable the expression of their natural behaviours.

Figure 1 An example of a contingent valuation questionnaire.

The implementation of the welfare improvement schemes will incur costs. It is proposed that to cover these costs, a levy (similar to VAT) is placed on food items. As a result, everyone's food bill will increase by the amount of the levy.

i) The government has decided to introduce ONLY the scheme that improves the welfare of laying hens by enlarging and enriching their cages, while all other farm animals remain in their existing conditions.

Would you be prepared to support the levy, if your foodbill rose by a month?

$$
\begin{aligned}
& \text { Yes } \\
& \text { No }
\end{aligned}
$$

ii) The government has decided to introduce ONLY the scheme that improves the welfare of broiler chickens, by using slower growing breeds, while all other farm animals remain in their existing conditions.

Would you be prepared to support the levy, if your food bill rose by a month?

$\begin{array}{ll}\text { Yes } & \square \\ \text { No } & \square\end{array}$

iii) The government has decided to introduce ONLY the scheme that improves the welfare of the dairy cow by changing their winter housing from cubicles to straw yards, while all other farm animals remain in their existing conditions.

Would you be prepared to support the levy, if your food bill rose by a month?

$\begin{array}{ll}\text { Yes } & \square \\ \text { No } & \square\end{array}$

iv) The government has decided to introduce ONLY the scheme that improves the welfare of pigs, by enlarging and enriching their living conditions, while all other farm animals remain in their existing conditions.

Would you be prepared to support the levy, if your food bill rose by a month?

Yes

No 
Animal welfare is valued by employing the contingent valuation method (Mitchell and Carson, 1989), a technique frequently used in valuing environmental goods. It is a direct survey instrument which involves the setting up of a realistic, hypothetical market. In this market, all the welfare improvement programmes are specified. The respondents are then asked how much they would be prepared to pay for each of the proposed improvements (see Figure 1). While this method derives the estimates of the value that is placed on animal welfare by the public, it also reveals their preference ordering. As individual values are produced for each improvement programme, the estimates reveal the order in which the schemes are preferred.

While the contingent valuation method produces an order of the preferences for the animal welfare improvement schemes, it cannot test for inconsistency alone. In order to test for consistency, other methods have to be used. Two other techniques employed are paired-comparisons and matching. Both produce the order in which the welfare programmes are preferred, enabling external consistency to be checked. Additionally, they test for internal consistency, through the way the preferences are revealed. If the respondents are

Figure 2 An example of matching.

The implementation of the welfare improvement schemes will incur costs. It is proposed that to cover these costs, a levy (similar to VAT) is placed on food items. As a result, everyone's food bill will increase by the amount of the levy.

Through this levy, suppose that a large government fund was to be made available to improve the welfare of farm animals. This fund has been initially allocated to improve ONLY the welfare of laying hens in the UK through enlarging and enriching their cages, as outlined in the information booklet. This will result in 10 million laying hens having their welfare improved, while all other farm animals remain in their existing conditions.

However, this fund could be used instead to improve the welfare of dairy cows through changing their winter housing from cubicles to straw yards, as outlined in the information booklet. How many cows would have to have their welfare improved for you to prefer the money to be spent on cows rather than laying hens?

Answer internally inconsistent, a unique order of their preferences cannot be produced.

In paired comparisons (Edwards, 1957), the respondents are presented with the welfare improvement schemes in pairs and have to select their preferred option. All potential combinations are shown randomly. Respondents must state which of the pair they prefer, any other answers i.e. 'don't mind' are not allowed. Matching (Tversky et al., 1988) is similar to paired-comparisons, as respondents are offered pairs of schemes. However, additional information about the numbers of animals affected through implementing only one of the programmes is given. The respondent has to state the number of animals which would have to have their welfare improved in the alternative scheme, for that scheme to be chosen instead of the initial programme (see Figure 2). The number given by the respondent indicates which option is preferred, i.e. if the response is less than the original figure, then the alternative is favoured over the first proposed. In both paired comparisons and matching, a valid order of preferences can only be revealed if the respondent is internally consistent. External consistency can be checked by comparing the orders of preferences revealed by each of the methods.

The contingent valuation produces a value for the willingness of the public to pay for specific animal welfare improvements, while all the different methods reveal the order of the public's preferences for the different animal welfare schemes. As a variety of techniques is used, different orderings of preferences could potentially occur, indicating inconsistency. Any inconsistencies that are present challenge the validity of the values gained from the contingent valuation, and possibly the public's ability to articulate rationally their preferences on these issues.

\section{References}

Edwards, A. L. 1957. Techniques of attitude scale construction. Appleton-Century-Crofts, Inc., New York.

Mitchell, R. C. and Carson, R. T. 1989. Using surveys to value public goods: the contingent valuation method. Resources for the Future, Washington DC.

Tversky, A., Slovic, P. and Sattath, S. 1988. Contingent weighting in judgement and choice. Psychological Review 95: 371-384. 